\title{
Corporal Punishment in Schools: Issues and Challenges
}

\author{
*Gudyanga $\mathrm{E}$ \\ *Mbengo $\mathrm{F}$ \\ ${ }^{* *}$ Wadesango $\mathrm{N}$ \\ *Midlands State University, Faculty of Education, Zimbabwe, nwadesango@ufh.ac.za \\ ${ }^{* *}$ University of Fort Hare, TLC, East London, RSA
}

\section{Doi:10.5901/mjss.2014.v5n9p493}

\begin{abstract}
In this paper the researchers sought to examine the issues and challenges surrounding the notion of corporal punishment in schools. The study was based on secondary data collected through review of studies, reports and policy documents. A thorough analysis of concepts related to corporal punishment such as context of $\mathrm{CP}$, relationship between $\mathrm{CP}$ and physical abuse, whether $C P$ promotes or controls deviant behaviour, the relationship between $C P$ and moral internalisation, does $C P$ enable behaviour reform, $C P$ and school pupils retention, $C P$ and cognitive development was done in an endeavour to establish the relationship between $\mathrm{CP}$ and behaviour change. The study found that teachers and school heads only match rules to be observed with commensurate punishments, threats and warnings but spend no quality time on explaining why this is acceptable while that is unacceptable thereby not equipping pupils with morals that can substitute deviance. As a result CP did not serve its purpose in schools.
\end{abstract}

Keywords: Corporal punishment, deviant behaviour, moral internalisation, behaviour change

\section{Introduction}

As the school administrators and classroom teachers use corporal punishment in recommended and non-recommended ways respectively to deal with deviance, some deviant pupils find themselves pulling out of school due to non-conformity or non-tolerance to the controlling measure applied on them, 'corporal punishment.' Some pupils aggravate or learn methods of continuing with the deviant behaviour clandestinely. There are some people who were deviant during their school going days and have kept on with such tendencies such that the deviant behaviour has matured in them despite being exposed to corporal punishment at school. They continue to display deviance even as they are now adults.

The fact that corporal punishment, a strategy for controlling deviant behaviour was once abolished in Zimbabwe and later bounced back into the system, shows that the strategy is a force to reckon with when it comes to behaviour control. Also, most teachers and school heads usually use corporal punishment as a last resort for disciplinemaintenance which is a clear testimony that some effectiveness and significance in deviance control is attached to corporal punishment by its users. However, the effectiveness of corporal punishment in controlling deviance in schools, though it is a recommended strategy, seems doubtful as evidenced by its abolishment and reintroduction even after being contested against by the supreme court of the land.

Some pupils, worldwide have even failed to complete their primary and basic education due to factors linked to the use of corporal punishments especially on institutions where the administrators and teachers believe in corporal punishment as the principal strategy to control pupils' behaviour (United Nations 2008, Stearns \&Glennie, 2006). In such situations, which result in drop-outs, one wonders whether corporal punishment yields the intended effective results. When corporal punishment is administered, is it the bad behaviour being fixed or one's personal life? Does pain on the flesh rehabilitate one's behaviour? Should we nail one's future chances of success in education just because they have shown deviant behaviour, for example on a case where dropouts result from perpetual, very frequent and severe corporal punishment? In this case is it the bad behaviour being fixed or one's personal life? Again the question arises as to whether the physical punishment remains corporal punishment or has escalated to physical abuse.

The prevalence and recurrence of deviant behaviour in schools, and its devastating effects to education together with the erratic and seemingly contingent strategy of corporal punishment being employed to deal with deviance, but to no avail or with little success, has prompted the researcher to investigate this technique of corporal punishment that 
school teachers and administrators use in controlling deviant behaviour in schools with the goal of establishing its effectiveness as a pure corporal punishment uncontaminated with abuse.

\section{Context of Corporal Punishment in Zimbabwe}

Before going any further, the scope of corporal punishment under investigation in this study is the one that is mild, non injurious, infrequent and purported at controlling pupils' behaviour. There is a difference between corporal punishment (physical punishment) and physical abuse. Gershoff (2002) in her meta-analytic research on the effects of corporal punishment says that studying the true effects of corporal punishment requires drawing a boundary line between physical punishment and physical abuse.

Bourke, (1981:53) also says, "Corporal punishment should be for the purpose of correction, control or discipline and that is reasonable having regard to: the age of the child, the method of punishment, the child's capacity for reasoning and the harm caused to the child." The child's capacity for reasoning is very important as it enables moral internalisation by the children and realisation of their misdeeds which is obviously the basis for behaviour reform. In addition, both physical and psychological harm to the children as a result of corporal punishment is not the intention of such a strategy.

Bourke shares the context in which pure corporal punishment undistorted by physical abuse can be perceived. Once physical punishment ceases to take into considerations the above factors and many others then it can easily escalate to physical abuse, though it may not be so intentionally. Gershoff (2002) further contends that the severity and frequency of corporal punishment also matters. By implication, the more often or more harshly the children are hit the more likely they are to be physically abused. Therefore frequency and severity can be used to distinguish corporal punishment from physical abuse.

Gershoff (2002) contends that the act of corporal punishment itself is different across parents - parents, vary in how frequently they use it, how forcefully they administer it, how emotionally aroused they are when they do it, and whether they combine it with other techniques or not. These mentioned qualities also determine whether the physical punishment can be described as physical abuse or corporal punishment both at home and at school. In the Zimbabwean context, corporal punishment of pupils in schools is highly guarded from escalating to physical abuse though in rare cases it may slip into an abuse. These are cases in which the proper laid down procedures for administering corporal punishment would have been overlooked. Unlike at home the practice of corporal punishment within the school is done following stipulated procedures on how to discipline the pupils. The school heads are prescribed to keep records of all cases of corporal punishment that they administered in schools. This on its own informs the heads that they do not have to administer a severe punishment that may hurt children since the records would be available to show that they once punished the pupils and may be held accountable should any mishap related to the corporal punishment administered unfold.

In fact corporal punishment in Zimbabwean schools is recommended for use as one of the last options in pupils' behaviour control and correction. This is quite vital since it avoids overuse and reliance on corporal punishment which in turn becomes physical abuse. Also, the types of offences that attract corporal punishment in a school are clearly spelt out to avoid it being used on very minor offences which would promote its frequent use and culminate to abuse. However even with all these protective procedures put in place, use of corporal punishment still remains a contravention of the United Nations Convention on the Rights of the Child that outlaws the use of corporal punishment in schools, and which Zimbabwe ratified in 1992 (U.N. General Assembly, 1989).

Also, the physical punishment that teachers unofficially administer in classrooms is investigated for its effectiveness. This is very important because the deviant pupils are usually referred to the school head for formal corporal punishment from the classroom where they display these deviant behaviours that are incompatible with the education process. There is a strong belief, that just like parents at home; a classroom teacher may abuse physical punishment in a class which end up affecting the effectiveness of formal corporal punishment administered legally by the school administrators. However, it should be noted that in the context of this study, corporal punishment in class by the teacher is not perceived as an abuse as long as it is infrequent, not severe to injure and not employed for very minor offences like forgetting a pen at home.

\section{Is Corporal Punishment the Same as Physical Abuse?}

Although many adverse effects are associated with corporal punishment in a variety of researches, it can be argued that in most cases corporal punishment has been misrepresented as physical abuse. Baumrind, Larzelere and Cowan (2002) say that a high association between corporal punishment and physical abuse is not enough evidence that mild to 
moderate corporal punishment is identical to physical abuse or that it increases the risk of abuse. The argument is that there should be a clear distinction between corporal punishment and physical abuse. It may be difficult to draw the line between these two but that does not mean it is impossible or that they become one and the same thing.

Furthermore, the fact that corporal punishment can easily escalate to physical abuse is not a valid reason to brand corporal punishment as physical abuse and further attribute all the nasty consequences and experiences from physical abuse to corporal punishment. Benatar (2004) in his philosophical study of corporal punishment says clearly that there are instances of abusive corporal punishment, but that is insufficient to demonstrate even a correlation between corporal punishment and physical abuse and prove a causal relationship.

Shumba (2003) points to the findings of a study conducted a year after corporal punishment by parents was abolished in Sweden. Evidence suggested that Swedish parents were as prone to serious abuse of their children as were parents in the United States, where corporal punishment was still legalised. This exposes the fact that not only corporal punishment is likely to result in abuse, but other techniques can equally if not more, likely to result in abuse.Abolishment or absence of corporal punishment is not a guarantee to achieving zero physical abuse of children.

In addition, the fact that there are some parents and teachers who inflict physical punishment in an abusive way does not entail the conclusion that corporal punishment has the same effects as physical abuse and that corporal punishment should never be inflicted on anybody. If it did have this entailment, then for example, the consumption of alcohol by anybody prior to driving would have to be condemned on the grounds that some people cannot control how much alcohol they consume before driving. Just as we prohibit the excessive but not moderate use of alcohol prior to driving, we also in the same way condemn the abusive but not the mild and infrequent use of corporal punishment.

Beckett (2005) argues that we are not in a position to presuppose a clear casual link between corporal punishment and adverse child outcomes and as a result, should be wary of applying the findings of a correlation research to social policy decisions such as abolishment of all forms of corporal punishment. Because available evidence shows no serious harm from mild and infrequent corporal punishment, there seem to be poor grounds for suggesting that the punishment should be regarded as unacceptable and be abolished.

\section{Does Corporal Punishment Promote or Control Deviant Behaviour?}

The effectiveness of corporal punishment in reforming and controlling children's behaviour is very contentious and much debated within societies. The debate is so polarised that the issue leaves those in debate on either, the side of those calling for its abolishment or those who cherish and defend its existence and use in schools. No quality time has been spend on examining the true nature of corporal punishment as well as weighing its advantages and disadvantages in an effort to find ways of developing or improving it. There is need to have guidelines that help to prevent corporal punishment from sliding to physical abuse that has adverse effects, into a more helpful and fruitful technique of disciplining pupils.

Researches that criticise the effectiveness of corporal punishment dwell much on the disastrous effects of using 'corporal punishment' with very little to no effort to suggest improvements to make it acceptable as any other technique for behaviour correction. A research carried out by Smith et al. (2004) on the guidance and discipline of children suggests that corporal punishment as a method of disciplining children is both ineffective and harmful. Linke (2002:28) says, "Corporal punishment teaches a child that problems can be addressed through physical aggression thereby increasing more disciplinary problems in class." It can be concluded that punishing a wrongdoer by inflicting pain conveys the message that violence is an appropriate way to settle differences or to respond to problems. One teaches the child that if one does not like what somebody does, it is acceptable to inflict pain on that person. It becomes a contradiction especially in those cases where a child is hit for having assaulted another child. When this happens, it is claimed, the child is given the violent message that violence is wrong. The children are told that they were wrong to commit an act of violence yet the parent or teacher conveys this message through violence. These messages are then acted upon by the child who is hit. It is claimed that in short term those who are physically punished are alleged to commit violence against other children, against teachers and against school property. As for long term effects, it is alleged that significant numbers of people who commit crimes were physically punished as children. Therefore, violence breeds violence.

In contrast to the above argument, the message implicit in violence seems to prove too much. If we suggest that hitting a wrongdoer imparts the message that violence is a fitting means to resolve conflict, then surely we should be committed to saying that detaining a child or imprisoning a convict conveys the message that restricting liberty is an appropriate manner to deal with people who displease one. We would also be required to concede that fining people conveys the message that forcing others to give up their property is an acceptable way to respond to those who act in a way that one does not like (Benatar, 2004). 
For those who advocate for removal of corporal punishment and replace it with therapy, it would also convey the message that people with whom one disagrees are to be viewed as sick deserving of treatment. If beatings send a message, why don't detentions, imprisonments, fines and a multitude of other punishments or disciplinary techniques convey equally undesirable messages? The argument proves too much because it proves that all punishments convey inappropriate messages and is wrong. This conclusion is absurd.

It is the researchers' conviction that punishing children when they do wrong seems to be one important way of teaching children that there is all the difference in the world and in fact a vast difference between legitimate authorities such as the judiciary, parents, teachers and those using punitive powers responsibly to punish wrongdoing and children or private citizens going around beating each other, locking each other up and extracting financial tributes. To suggest that children cannot extract this message, but only the cruder version that the objection suggests is to underestimate the expressive value of corporal punishment and children's ability to comprehend it.

It is arguable that corporal punishment can be effective in controlling deviant behaviour because when teachers employ it to control pupils' behaviour, it signalises a failure on the part of the teachers to discourage deviance using other ways such as by moral authority, a system of rewards or by milder punishments. Researches suggest that it is often a headache for some teachers to maintain classroom control in school because 'many teachers fail to foster an atmosphere of mutual respect' between their pupils and themselves or as originating in failed pedagogical relationships; Mushoriwa and Shumba (2002). It can be admitted that these teachers lack the ability or inclination verbally to communicate expectations to children. It is also true that when teachers resort to corporal punishment this indicates that their prior efforts to discourage the wrongdoing failed.

Although the above assertion might be the correct explanation for the use of corporal punishment by teachers, there is a big difference between a failure in the pupil and a failure in the teacher. In some sense it is a fact that the teacher has failed to prevent failure in the child. The failure to avoid using corporal punishment for child behaviour control cannot be solely blamed on the teacher excluding the pupils, parents and other factors that might contribute to this failure. This is because the school pupil behaviour may be a reflection of the wide socialisation patterns to which the child is exposed to in the community (Shumba and Moonrad, 2001).

Moreover, if we hold on to the opinion that corporal punishment indicates failure by the teacher then it might also mean that it also indicates failure of the still earlier efforts like detaining the child which equally indicate the failure of still earlier efforts of admonition which in turn indicate failure of the still earlier efforts like moral example. Upon realising this, it becomes clearer why, although it is the case that earlier efforts may have failed, it is not sufficient to say that the failure is in the teacher. To insist on this would lead to the conclusion that the teacher is responsible even for the child's not following the teacher's moral example.

If a child discontinues deviant behaviour after administration of corporal punishment, then it is a sign of the punishment's ability to control behaviour. However, this may gradually happen as the pupils disengage themselves from their habits slowly. Once the deviants behaviour becomes reduced or is completely eradicated then the pupil can work or be guided towards behaviour reform. In this whole process not corporal punishment alone should be used but also other techniques should be employed at appropriate times.

\section{Does Corporal Punishment Promote Moral Internalisation?}

Kerr, Lopez, Olson and Sameroff (2004:374) say, "Moral internalisation is the internalisation of values and attitudes of a society by children in order that they guide their behaviour." The values and attitudes internalised by children help them to screen wrong and right behaviour. Moral internalisation should be coupled with moral regulation which includes sensitivity to wrongdoing, appropriate conduct and the ability to restrain one self from misbehaviour as well as correcting damage.

Holden (2002) and Wissow (2002) are of the same perspective that for moral internalisation to prevail, children should be exposed to positive discipline and not punishment. Positive discipline does not inflict pain on children but rather avails guidance to children's moral, emotional and physical development. This enables children to take responsibility for their actions. Positive discipline, according to Shumba (2003), also helps children to understand why some behaviour is acceptable or not.

On the other hand, negative discipline promotes forced compliance instead of internal control (evidence of achieved moral internalisation) by stipulating on doing what one is told in order to avoid an unpleasant experience that in this case is corporal punishment. Excessive use of power-assertive discipline in the absence of induction or explanation may have the opposite results from what such discipline is intended to achieve.

Gawlik, Henning and Warner (2002); Smith, Gollop, Taylor and Marshall (2004) say that the desired outcome of physical punishment is child compliance with adult directives. This is only short term and immediate compliance and is far 
from moral internalisation. Immediate compliance is the only positive outcome that is said to be associated with 'corporal punishment' amid numerous negative immediate and long term effects.

Smith et al. (2004:12) say, "Corporal punishment is associated with increased child aggression, antisocial behaviour, lower intellectual achievement, poor quality of parent-child relationships, mental health problems, for example depression and diminished moral internalisation." Martin and Stein (2012), also contend that corporal punishment has numerous adverse psychological effects, including depression, inhibition, and rigidity, lowered self esteem and heightened anxiety. In face of these negative outcomes predicted by physical punishment, it becomes difficult for it to change pupils' deviant behaviour for better especially when associated with diminished moral internalisation.

Although there is evidence that excessive corporal punishment (physical abuse) can increase the chances of such psychological harm, most of the psychological data are woefully inadequate to the task of demonstrating that mild and infrequent corporal punishment has such consequences.

It is claimed that corporal punishment is an effective form of punishment because it deters those punished from further wrongdoing. For punishment to be effective it must follow wrong doing instantaneously and also follow every (at least nearly every) act of wrong doing (Beltran, 2002). When parents are consistent in their disciplinary strategies, children learn what to expect from their parents if they misbehave. Children are less likely to test boundaries or push limits that are firmly set when they know the consequences of bad behaviour. Therefore the punishment would have to be inflicted even more regularly than it already is thereby transforming it to physical abuse since it won't be infrequent anymore.

However, it can be argued that deterrence is not all. A punishment can have some deterrent effect without being extremely effective. The mere continuous existence of wrongdoing does not demonstrate the failure of corporal punishment as a deterrent. To know how effective corporal punishment is one must know what the incidence of wrongdoing would be if prior punishment for it had not been inflicted. It is also arguable that increased frequency improves the deterrent effect, as the reverse might be true. The expressive function surrounding a particular form of punishment might well be enhanced by inflicting it less often. If one uses physical punishment infrequently, it can speak louder than if one inflicts it at every turn. The special status accorded to it by its rare use might well provide psychological reason to avoid it out of the proportion to its actual severity.

Dzurgba (2000) contends that the deterrent approach is a theory of punishment which rests on the understanding that the purpose of punishing wrongdoers or criminals is to deter, prevent or frighten other people from doing the same wrong act. Balogun (2009:49) says, "Punishment as a deterrence may deter potential criminals or offenders from carrying out the same wrong later in future." Balogun (2009) drives straight home the point that punishment does not deter children from wrongdoing only for a short time when he says that punishment deters even same wrongdoing later in life.

This is in sharp contrast to the claim that corporal punishment only achieves forced and short lived compliance at the expense of moral internalisation, and only committed compliance and not forced compliance is the first step towards internal control (Kochanska, 2001). If punishment can deter same wrongdoing later in life, then all it means is that such wrongdoings are not repeated and the child will be on course to reform. If corporal punishment encourages lazy pupils to do their schoolwork through reminding them of the ordeal experiences then the pupils might end up used to doing their work, thereby gradually reforming their behaviour towards schoolwork. Punishment here works as a motivator, but eventually makes the habit of working hard fixed in the pupils. Even before that, by being able to deter pupils from behaving badly, it also shows that punishment would have been successful in controlling deviant behaviour.

It is quite correct that inductive discipline sets limits, sets logical consequences, reasoning and explanation that aid moral internalisation in pupils. In contrast, corporal punishment is power assertive discipline which can be perceived as a follow up with threats, smacks and privileges withdrawal for something inappropriate done. However, for the corporal punishment under study here, is the punishment used for the purposes of reinforcing or consolidating moral internalisation. It takes pupils to responsibility for their actions. This is so because at school when authorities opt for the use of corporal punishment, it is taken as a last resort when all other methods of positive discipline would have failed to deliver. It is not a strategy that is solely used for discipline maintenance but is used in conjunction with other techniques.

Without moral internalisation there cannot be any meaningful behaviour reform except immediate compliance only. The claim that corporal punishment does not teach or that it deters moral internalisation can be disputed by the fact that whenever corporal punishment is administered, it is a response to an unacceptable behaviour and as pupils are punished they can distinguish acceptable behaviour from that which is not acceptable. To think that pupils are punished only to force compliance and not for moral internalisation is tantamount to claiming that pupils are punished for the behaviours that they can't distinguish whether they are acceptable or not and in such cases the punishment would be far from being the corporal punishment under this study but enough to be classified as physical abuse. 


\section{Does Corporal Punishment Enable Behaviour Reform?}

Talwar, Carison and Lee (2011) carried out a study involving two private schools in a West African country on the effects of a punitive environment on children's executive function. They found out that in the short term, corporal punishment may not have any diverse effects, but if relied upon over time it does not support children's problems solving skills or their ability to inhibit inappropriate behaviour. The research also found that pupils in a harsh punitive environment tend to lie. They concluded that harsh discipline fosters dishonesty in young children. In that study, pupils from a school that relied on corporal punishment lied and strongly defended their false position in order to avoid punishment. However their colleagues from another school with a different approach to discipline whom they had connived with, eventually told the truth, in defiance to maintenance of the false position in order to avoid corporal punishment.

Talwar and colleagues compared children from a school that used positive behaviour control techniques with the other that had excessive use of corporal punishment which is obviously an abuse. The study is said to have been carried out with pupils from the other school where discipline in the form of beating with a stick, slapping in the head, and punching was administered publicly and routinely for offenses ranging from forgetting a pen to being disruptive in class. Surely, this is not the type of corporal punishment recommended by our statutory instrument in Zimbabwe education sector.

The findings of the above outlined research expose yet another common error of referring to physical abuse as corporal punishment. In the above research findings, the phrase 'relied upon' is the distinguisher. Once corporal punishment is relied upon for every offense or mistake, then it ceases to be one, but becomes physical abuse due to high frequency in its use. Again, it can be said that the dire consequences of physical abuse pushed the children into a corner where only lying would rescue them from unbearable abuse. They knew from experience that freedom of expressing the truth was given but freedom after expression wasn't guaranteed as abuse would follow.

In the above research by Talwar et al (2011), it is said that even minor offences such as common mistakes like forgetting a pen would end up in corporal punishment. It shows that corporal punishment was routinely and publicly administered from minor to serious offences. The punishment was indiscriminate and the gravity of offenses not discriminated in order to accord a punishment commensurate to an offense. In contrast, the corporal punishment under this investigation is usually not administered publicly as this would abuse pupils by humiliating and dehumanising them as they have not fully established self confidence.

\section{Corporal Punishment and School Pupils' Retention}

United Nations' (2008) survey to determine the use of corporal punishment reports that 35000 school children in Pakistan dropout from school each year due to corporal punishment. Such beatings at schools are also responsible for one of the highest dropout rates in the world, which stands at $50 \%$ during the first five years of education. Dropping out is a term used to describe the withdrawal of pupils from school prematurely. The report by the United Nations exposes the retrogressive nature of corporal punishment to the education process of the young children. When pupils leave school at such a tender age then the foundational purpose of the education process would have been entirely defeated. Stearns and Glennie (2006), note that factors internal to the school, such as disciplinary policies, in particular corporal punishment or conflicts with students might serve to push students out of school.

Pupils who dropout from school have nothing to show for the time that they spent at school due to absence of any graduation certificate to substantiate that they have been to school (Ajaja, 2012). Consequently, such people have limited participation in pertinent societal decision making processes e.g. in politics. Instead of them contributing meaningfully for the development of the nation they become liabilities and exert pressure on the demand for social services from the government (Azzam, 2007).

Smart et al's (2008) research from the longitudinal study of Australian children shows that inconsistent parenting is strongly associated with behavioural problems in children, including conduct problems, low pro-social behaviour, hyperactivity, emotional difficulties and problems relating with peers. The inconsistent treatment given to the pupils can also be in form of corporal punishment administered at school for misbehaviour while facing nothing of that sort at home. Such inconsistence between the home and the school can be the best explanation for school dropouts related to corporal punishment. The school becomes a more harshplace than the home and refuge is sought at home, leading to dropouts. This can also be in contrast to the pupils coming from a cultural background where corporal punishment for wrongdoers is cherished and used to achieve justice. Such pupils find nothing absurd about it. The effectiveness of corporal punishment is affected and therefore associated with cultural persuasion. 


\section{Corporal Punishment and Cognitive Development}

Straus (2001:53) says, "Verbal disciplinary methods that include explanation and reasoning provide the child with more cognitive stimulus." Pupils who are anxious about being physically punished are prohibited from exploring their physical and social worlds from which they learn and as a result they are less likely to extend their cognitive skills. In other words, pupils' cognitive development is deterred or impaired by fear when corporal punishment is used. Neuter (2011) contends that teacher-pupils relations are very important for the child's cognitive development. The social perspective on development also suggests that children's cognitive development emerges out of social interaction. This interaction includes teacher-pupil relationships which may be weakened by use of corporal punishment as it may lower the pupils' motivation to learn.

This study focuses on the effectiveness or the degree to which corporal punishment as a remedy is able to control pupils' behaviour. However, the research by Smith et al. (2004), a longitudinal study of Australian children showed that behavioural problems were strongly linked with higher levels of parental hostility, with children being four times more likely to have conduct problems and twice as likely to have hyperactivity problems when experiencing hostile parenting. Evidence from the research also suggests that warmth and affection in parent-child relationships is linked with more positive outcomes for children. Berk (2009) also concurs with the above statement when he says that parental warmth has been shown to increase children's self esteem and reduce the risk of psychological and behavioural problems. High self esteem is another ingredient for cognitive development and motivation. Usually, pupils who do well in academic work are not those with behavioural problems.

The link between hostile parenting such as the use of corporal punishment and behavioural problems in children is one of major concerns to the school. This is the background information vital in order for teachers to understand their pupils' behaviour at school. This reinforces the idea of investigating the type of punishment that the child gets at home inorder to establish its impact on the effectiveness of corporal punishment at school. For example where the punishment used at home is further reinforced at school.

To further show that the school and the home affect each other on the strategy that they use to maintain discipline, the fact that hostile parenting practice such as corporal punishment are linked to parent-child relationships and other behavioural problems is an explanation that the same problems can be experienced at school as the teacher acts in locoparentis. Teacher-pupil relationships can greatly affect the effectiveness of corporal punishment in controlling deviance and achieve discipline. Also, if hostile parenting can impair cognitive development the same applies to corporal punishment, regarded as a hostile technique of discipline maintenance and so is not immune to causing psychological and behavioural problems at school as well.

In light of the above point it also follows that techniques such as sending the deviant pupil back home to bring parents, timeouts, manual work punishment or child detention equally short-changes the cognitive development of deviant pupils. This is so because these techniques exclude the deviant pupils from classes for a considerable learning time. Only lost ground can be recovered but lost time can never. With corporal punishment a very limited time is lost during which the pupil is punished and thereafter comes back to the classroom for lessons.

Sometimes, techniques that exclude pupils from classes may work in favour of deviant pupils or in furtherance of deviance as pupils may misbehave whenever they feel that they need a break from classroom activities or when they have neglected their schoolwork and are unable to provide it to the teacher when it is due. This may further promote behavioural problems and at the same time cost the pupils' cognitive development. Pupil's detentions or quarantines may also result in psychological problems and demoralisations as children desperately need social interaction for growth in social and cognitive spheres.

\section{Conclusion}

Corporal punishment has been described as infrequent and mild pain applied to the pupils for the purposes of behaviour control. It is different from physical abuse on frequency and severity. It has also been noted that corporal punishment has the ability to deter, control deviance and also reinforce, but not instil moral internalisation. When abused, it can have adverse effects on cognitive, emotional and moral development and contribute to an increase in school dropouts. Therefore it is not a defect free technique just like any other techniques. Cultural orientations of the pupils and home discipline factors also have a role to play on the effectiveness of corporal punishment in controlling and reforming deviant behaviour in pupils. This study made a review of established theories on the effectiveness of corporal punishment. This is where the definition of corporal punishment was established and the distinction between corporal punishment and physical abuse identified. Factors that qualify a punishment as physical abuse were identified as frequency, severity, 
gravity of offenses to which it is applied and the emotional state of those inflicting the punishment. However, it was also established that even the recommended corporal punishment can easily slip into physical abuse. Deviance has also been linked to cultural orientation of the pupils. This orientation has a great impact on the effectiveness of corporal punishment.

\section{Recommendations}

When teachers and school heads carry out redirection, discipline or punishment they must include an explanation of why a particular behaviour is unacceptable and what behaviour is acceptable. This is because many in most cases, a child's misbehaviour is a mistake in judgement.

\section{References}

Ajaja, P.O. (2012). School Dropout Pattern among Senior Secondary Schools in Delta State, Nigeria. International Education Studies, 5 (2): $145-154$

Azzam, A.M. (2007). Why students drop out? Educational Leadership, 64(7): 9193.

Balogun, O.A. (2009). A Philosophical Defence of Punishment in Traditional AfricanLegal Culture: The Yoruba Example. Journal of Pan African Studies, 3 (3): 43-54.

Baumrid, D., Larzelere, R.E and Cowan, P.A. (2002). Ordinary physical punishment: Is it harmful? Psychological Bulletin, 128(4): 580589.

Beckett, G.( 2005). The Swedish myth: The corporal punishment ban and child death statistics. British Journal of Social Work, 35: 125138.

Beltran, M. (2002). Parenting tips: The importance of consistency. From <http//wwww.essortment.com/family/parentingtipsiszdp.htm> (Retrieved on 6 January 2014)

Benatar, D. (2004). Corporal Punishment Philosophical Study. From <http/www.corpun.com/benatar.html> (Retrieved on 12 December 2013)

Berk, L.E. (2009). Child Development (8thed.).United States of America: Pearson Education.

Bourke, J.P. (1981). Bourke's criminal law. Sydney: Butterworth's.

Dzurgba, A. (2006). Principles of Ethics. Ibadan: Agape Publications.

Gawlik, J., Henning, T and Warner, K. (2006).Physical punishment of children. Hobart: Tasmania Law Reform Institute.

Gershoff, E.T. (2002). Corporal punishment by parents and associated child behaviours and experiences: A meta-analytic and theoretical view. Psychological Bulletin,128 (4): 590-595.

Kerr, D.C., Lopez, N.L., Olson, S.L and Sameroff, A.J. (2004). Parental discipline and externalising behaviour problems in early childhood: The roles of moral regulation and child gender. Journal of Abnormal Chid Psychology, 32(4): 383-390.

Kochanska, G., Coy, K.C and Murray, K.T. (2001). The development of self regulation in the first four years of life. Child Development, 72(4): 1091-1111.

Linke, P. (2002). Physical punishment: What does the research say? Every Child, 8(3): 28-29.

Martin. T and Stein, H.D. (2012). Paediatrics and Adolescent Medicine, Journal Watchdog, 3:23-26

Mushoriwa, T.D and Shumba, A. (2002). Self-Perceived and Measured Study Strategies Among College Students. South African Review of Educational Journal, 2(1): 46-49.

Nauert, R. (2011). Physical Punishment May Impair Child's Cognitive Functions. Psych Central. From <http://psychocentral.com/news /2011/07/27/ (Retrieved on 12 December 2013)

Shumba, A and Moorad, F. (2001). A Note on the Laws Against Child Abuse in Botswana.

PULA. Botswana Journal of African Studies, 14 (2): 175-181.

Shumba, A. (2003). Pupil Physical Abuse by Secondary School Teachers in Zimbabwe: A Child-Rearing Practice or Cultural Dilemma? Journal of Aggression, Maltreatment \& Trauma, 8(4) :143-159.

Smith, A.B., Gollop, M.M., Taylor, N.J and Marshall, K.A. (2004).The discipline and guidance of children: A summary of research. Dunedin, NZ: Children's Issues Centre.

Stearns, E and Glennie, E.J. (2006). When and Why Dropouts Leave High School. Youth and Society, 38(1): 29-57

Straus, M.A. (2001). New evidence for the benefits of never smacking. Society, 83(6): 52-60.

Talwar, V., Carison, S.M and Lee, K. (2011). Effects of a punitive environment on children executive function: A natural experiment. From <http: //www.sciencedaily.com/releases/2011/07/110726111109.html> (Retrieved on 4 January 2013)

United Nations General Assembly. (1989). November.Adoption of a Convention on the Rights of the Child. New York: Eangledon Press

United Nations. (2008). Pakistan: Corporal punishment key reason for school dropouts. UN Office for the Coordination of Humanitarian Affairs. From< http://www.iri nnews.org/Report.org/Report.aspx? Report=78275> (Retrieved on January 26, 2012).

Wissow, L.S. (2002). Child discipline in the first three years of life in Halfon Child Rearing in America; Challenges Facing Parents with Young Children. New York: Cambridge University Press 